\title{
Reflexiones constitucionales sobre el populismo democrático
}

Ignacio Fernández Sarasola

Universidad de Oviedo, España

(c) $\underset{\mathrm{Br}}{\mathrm{i}}$ 


\section{Reflexiones constitucionales sobre el populismo democrático}

Resumen: como movimiento político emergente, el populismo ha sido principalmente estudiado desde una dimensión sociológica y política, pero también puede analizarse a partir del Derecho Constitucional. En realidad, el populismo refleja el agotamiento de algunos de los principios esenciales sobre los que se ha sustentado el Derecho Constitucional occidental: la fe ciega en las encuestas electorales, el abuso de la democracia representativa (frente a la democracia directa), la falsificación de la forma de gobierno debido tanto a los grupos de presión como inadecuados usos en los partidos políticos, o la pérdida de poder de los medios de comunicación tradicionales, todo ello ha desembocado en una crisis constitucional que ha favorecido el crecimiento de los populismos.

Palabras clave: populismo, Derecho Constitucional, partidos políticos, grupos de presión, elecciones.

\section{Constitutional reflections on democratic populism}

Abstract: as an emerging political movement populism has been mainly studied from a sociological and political point of view, but it can be also analyzed through Constitutional law. In fact, populism reflects the exhaustion of some of the main principles of western Constitutional Law: blind faith in electoral polls, overuse of representative democracy (versus direct democracy), falsification of form of government due both to lobby system and bad habits in political parties or the loss of power of traditional mass media have all introduce a Constitutional crisis that have favored the growth of populisms.

Keywords: populism, Constitutional Law, political parties, lobby system, elections.

Fecha de recepción: 16 de febrero de 2017

Fecha de aceptación: 8 de marzo de 2017

Forma de citar APA: Fernández Sarasola, I. (2017). Reflexiones constitucionales sobre el populismo democrático.

Revista Filosofía UIS, 16(2), doi: http://dx.doi.org/10.18273/revfil.v16n2-2017013

Forma de citar (Harvard): Fernández Sarasola, I. (2017). Reflexiones constitucionales sobre el populismo democrático. Revista Filosofía UIS, 16(2), 283-301.

Ignacio Fernández Sarasola: español. Doctor en Derecho. Profesor titular de Derecho Constitucional de la Universidad de Oviedo. Secretario del Seminario de Historia Constitucional "Martínez Marina".

Correo electrónico: sarasola@uniovi.es

* Artículo de investigación científica y tecnológica. 


\section{Reflexiones constitucionales sobre el populismo democrático}

\section{Las muchas caras del populismo}

Desde hace menos de un lustro han proliferado de forma global planteamientos políticos que desatan por igual el interés (y en algún caso la preocupación) de estadistas, politólogos, juristas y sociólogos. Planteamientos en exponencial crecimiento que, con escasa precisión, tratan de reunirse en un cajón de sastre conceptual definido bajo la etiqueta de "populismo". Partiendo de la convicción de que es posible identificar su "esencia" (Zanatta, 2014, p. 18), dicho término suele aplicarse a posiciones políticas que, haciendo uso de ideas demagógicas ${ }^{1}$, simplistas o difícilmente realizables, pretenden movilizar a la masa social a través de procesos electorales o plebiscitarios.

El término ha servido por igual para designar situaciones muy distintas: la emergencia de partidos políticos que movilizan amplios sectores del electorado con un discurso radical, ora de izquierdas (el Partido Socialista Unido de Venezuela, el Partido de los Trabajadores brasileño, Podemos, en España, el Movimiento Cinco Estrellas en Italia o Syriza, en Grecia) ora de ultraderechas (el Frente Nacional francés, la Alianza por el Futuro de Austria, Amanecer Dorado en Grecia o el Partido de la Libertad holandés), el inesperado triunfo electoral de líderes aupados con campañas teñidas con un discurso radical (Donald Trump), así como ciertos resultados plebiscitarios (el "no" al Proceso de Paz colombiano, el Brexit británico o el reciente rechazo al referéndum de reforma constitucional italiano) o la agudización de añejos nacionalismos territoriales (Cataluña, en España, o Escocia, en Gran Bretaña). Un elenco de situaciones muy distintas que sólo pueden conectarse a costa de una burda simplificación: desde luego, poco tienen que ver los inesperados resultados en el plebiscito colombiano (en los que

\footnotetext{
${ }^{1}$ Sin que, por cierto, se explique qué son tales. Muy habitualmente se considera como demagógica simplemente una postura contraria a posiciones políticas dominantes.
} 
resulta imposible abstraerse del intenso componente sentimental que acompañó a la emisión del voto), con el Brexit (con una Gran Bretaña que siempre ha sido poco europea, que reusó a ingresar en la moneda común y que cuenta con una Commonwealth que garantiza sus expectativas comerciales). Pero lo que sí es cierto, es que en todos estos casos ha existido un discurso de fondo que apelaba sobre todo al sentimiento ciudadano, a la visceralidad más que a la lógica.

En realidad, la preocupación que muestran determinados académicos, políticos, empresarios, intelectuales y medios de comunicación hacia lo que adjetivan de "populismo", deriva de que su presencia convierte en imprevisibles los resultados de los procesos electorales y plebiscitarios. Acostumbrados a hacer una prognosis bastante certera, se encuentran ahora con que las encuestas previas sirven de bien poco, ya que resultan constantemente desmentidas cuando tiene lugar el recuento de sufragios. Algo no parece cuadrarles. Con el populismo se refieren, entonces, a las respuestas contrarias al sistema establecido; tiene por elemento común (casi siempre) un planteamiento "antisistema", un voto de castigo hacia el establishment político ${ }^{2}$.

El análisis de ese mal llamado populismo puede abordarse obviamente desde muchos prismas: económico, sociológico, politológico... También desde un punto de vista constitucional, porque las Constituciones nacionales no sólo admiten en su seno situaciones como las descritas (a fin de cuentas, todos los procesos mencionados se desarrollaron dentro de la legalidad constitucional) sino que, quizás, también los posibiliten. Habrá que determinar si, al amparo de la estricta forma constitucional, no se ha producido un cambio dogmático que ha favorecido que la aplicación del articulado constitucional dé lugar ahora resultados muy distintos a los que estaban arrojando hasta fechas muy recientes. En definitiva, es posible que la situación responda a un progresivo abandono del paradigma liberal-democrático a cuyo amparo surgieron la mayoría de las Constituciones actuales.

\section{La falaz confusión entre democracia y demoscopia}

Como se ha mencionado, parte de la preocupación con los "populismos" responde a la incertidumbre derivada de que los resultados en los procesos electorales y plebiscitarios disten de las previsiones que se habían efectuado. Así como el Derecho se basa en la previsibilidad (explicitada en la relación de causalidad normativa), la política también pretende en este sentido "objetivarse", buscando cierto grado de certidumbre que le permita anticipar los resultados que caben esperar.

\footnotetext{
${ }^{2}$ El problema de utilizar la idea de "antisistema" para definir estos planteamientos reside en que es un concepto del que se han adueñado (de forma un tanto impropia), las agrupaciones anarquistas y las contrarias al sistema económico mercantilista.
}

Revista Filosofía UIS, Vol. 16, No. 2, julio-diciembre de 2017 
La irrupción del principio de incertidumbre en el ámbito de la política parece, sin embargo, desconcertar a sus agentes. Y ello es así porque el sistema político liberal se ha ido forjando de tal forma que se promueve un cierto grado de certidumbre que ahora parece no producirse. Así, en algunos países esa certeza se consigue configurando un sistema electoral que reduzca el pluralismo político, organizando de este modo las demandas sociales en apenas unos pocos partidos políticos, o incluso apenas en dos, como sucede en los regímenes bipartidistas. Los sistemas electorales mayoritarios son los que logran este objetivo de forma más eficiente: al adjudicar todos los escaños en liza a la fuerza política más votada en una circunscripción, permiten que se reduzcan las opciones y, de este modo, se forja un modelo en el que previsiblemente sólo unas pocas fuerzas políticas lograrán alcanzar las instituciones representativas. Del mismo modo, la preferencia por mociones de censura constructivas entraña contar con Gobiernos más estables; las dificultades para utilizar instrumentos de democracia directa supone un mayor protagonismo de los partidos políticos, y así sucesivamente. Es obvio que las expectativas políticas se garantizan con previas selecciones normativas.

La estructura misma de muchas Constituciones representa un síntoma de esa misma previsibilidad. Siendo éstas, por regla general, rígidas, se incentiva el status quo y se genera un mayor grado de certidumbre: existe una probabilidad mayor de que el sistema constitucional permanezca inalterado, en relación con la posibilidad de que éste se enmiende. No todas las opciones tienen el mismo peso, ya que conservar la Constitución resulta más sencillo que enmendarla (De Otto, 1988, p. 98).

Ahora bien, esta "reducción de la incertidumbre" ha tratado de llevarse más allá del estricto plano normativo a medida que se ha incrementado el uso de las encuestas electorales. Y ahí reside parte del error: se ha concedido a estas encuestas un papel prácticamente jurídico, dando por sentado que los resultados que arrojaban se verían cumplidos en la realidad. La democracia ha tratado de venderse, pues, como demoscopia.

Se trata, obviamente, de un planteamiento erróneo, porque los factores que inciden en un resultado electoral o plebiscitario son tan abundantes que resulta extremadamente complejo realizar una previsión atinada. Cualquier evento de última hora o cualquier circunstancia imprevista pueden producir un vuelco en el voto, convirtiendo en inútiles todas las encuestas que con anterioridad se hubieran elaborado. Con frecuencia, además, la sociología electoral que suele interpretar las encuestas tampoco tiene en cuenta, en su análisis, la inabarcable cantidad de factores que influyen a la hora de depositar el voto. Los recientes resultados de las elecciones presidenciales estadounidenses representan un buen ejemplo de ello: antes de los comicios se aventuraba que a Hillary Clinton la respaldarían de forma clara las votantes y las minorías raciales, en tanto que Donald Trump contaría con el apoyo de ciudadanos blancos y con escasa formación. Sin embargo, las 
estimaciones finales parecen no corroborar estos resultados, o al menos no hacerlo con la claridad que se preveía. Según los indicios, las mujeres blancas, en especial las casadas, votaron prácticamente por igual a los dos candidatos; los votantes de raza caucásica universitarios se decantaron mayormente por Trump, en tanto que Florida, donde tanto peso tiene el votante hispano, fue clave para el triunfo del actual Presidente.

Todo ello no hace sino mostrar que los factores en concurrencia son muchos y difícilmente manejables por sociólogos y estadistas. El género del votante es, obviamente, un factor que ha de tenerse en cuenta cuando existen candidatos de distinto sexo, pero otros aspectos, como la raza o la posición económica, pueden interferir en aquel factor, convirtiéndolo en superfluo. No puede simplificarse la voluntad electoral al punto de considerar que cualquier mujer, por el hecho de serlo, va a preferir a una candidata; o que un votante hispano escogerá siempre al candidato de su misma extracción racial. Tales simplificaciones representan un insulto al propio elector, porque conducen a la idea de un voto automatizado, en virtud del cual se entiende que un determinado factor (sexo, raza, economía) ha de ser el único que el votante tenga presente a la hora de depositar la papeleta.

Otra circunstancia que no se tiene siempre presente es el hecho de que las propias encuestas no son neutrales, puesto que a la postre pueden acabar condicionando el voto (Gálvez Muñoz, 1991, pp. 797-818; Vera Estrada, 2008, pp. 32-37). Por ejemplo, si se vaticina que en un próximo plebiscito una de las opciones en liza ganará con extrema claridad, tal prognosis puede conducir a que los partidarios de dicha opción, considerando que su voto es innecesario, opten por no acudir a ejercer su derecho al voto; por el contrario, los afines a la opción contraria pueden movilizarse en mayor medida, con el objeto de intentar frenar el previsible resultado adverso. Y, con este cambio de papeles (abstención del hipotético ganador, participación masiva del previsible perdedor), los resultados obtenidos pueden ser justo los contrarios a los que se vaticinaban. Algo que, en buena medida, se verificó en el caso del Gran Bretaña con la consulta popular en torno al abandono de la Unión Europea: el triunfalismo de los contrarios al Brexit hizo que sus partidarios cobraran ventaja, acudiendo a votar en masa.

El error, en definitiva, consiste en considerar que la sociología electoral y las encuestas tienen un valor casi matemático, descuidando que la realidad discurre por otros derroteros: en la democracia las preferencias de los votantes dependen de factores complejos y muy difíciles de anticipar.

En términos constitucionales habría que determinar en qué medida la publicación de encuestas electorales no debería contar con severas restricciones. $\mathrm{Si}$, como parece demostrado, las propias encuestas pueden distorsionar el resultado electoral, quizás sería conveniente regular cuidadosamente aquellas, del mismo modo que se hace con las campañas electorales. Podría alegarse que 
cualquier restricción colisionaría de inmediato con la libertad de información o, en su vertiente pasiva, con el derecho a recibir información. Sin embargo, este derecho puede limitarse en virtud de la presencia de otros bienes constitucionales dignos de tutela, como puede ser el propio principio democrático. La conclusión de que las encuestas alteran los resultados electorales, del mismo modo que lo puede hacer un uso inadecuado de la publicidad electoral, permitiría restringirlas en aras de una mayor pureza del proceso electoral.

\section{La crisis del sistema de partidos y del lobby system}

Buena parte de la "sorpresiva" reacción electoral que se está produciendo en los Estados occidentales parece responder a una crisis anunciada del sistema de partidos y del "lobby system". Cuando en 1748 Montesquieu describía la Constitución de Inglaterra, hacía una descripción ideal de un sistema basado en el equilibrio constitucional que, sin embargo, no existía en la práctica, merced a la interferencia de las convenciones constitucionales. Algo parecido sucede hoy en día: el funcionamiento real de algunos sistemas constitucionales no parece corresponderse con la imagen teórica y formal de los mismos.

Esta circunstancia resulta especialmente perceptible en los sistemas parlamentarios -mayoritarios en Europa-, que presuntamente se basan en la idea de que la dirección política del Estado le corresponde a un Gobierno políticamente controlado por un Parlamento que está facultado para elegirlo y, por lo mismo, para destituirlo. La situación sería, pues, de colaboración estrecha entre dos órganos políticos que han de guardar entre sí una afinidad expresada a través de la relación fiduciaria que los une.

Ahora bien, esta imagen resulta totalmente distorsionada merced a la presencia en la ecuación de los partidos políticos. Cuestiones organizativas de los partidos, tales como la imposición de una severa disciplina de voto, acaban teniendo una repercusión inmediata en el funcionamiento del sistema parlamentario y, al mismo tiempo, en la percepción que de él tiene la ciudadanía. La imposición del voto a los integrantes del partido entraña, obviamente, que la totalidad de los representantes de esa formación política responderán de forma unánime a cualquier cuestión que se les plantee. Por más que constitucionalmente se establezca la prohibición de mandato imperativo, esa disciplina opera de facto, imponiéndose a la propia previsión de la norma magna. Situación que se agudiza más si cabe cuando a esa disciplina de partido se añade un régimen electoral que prevé listas cerradas y bloqueadas. El hecho de que sean los partidos los que deciden el orden de los candidatos -sin posibilidad alguna por parte de los electores de cambiar ese orden-garantiza a los partidos la fidelidad de los miembros de esas listas, so pena de verse relegados en ellas para sucesivos comicios. 
El resultado de todo lo anterior es que quien controla al Gobierno o puede exigirle responsabilidad no es el Parlamento, sino los distintos partidos que lo integran y que funcionan como bloques. A ello puede añadirse otra circunstancia: el sistema electoral puede estar proyectado de tal forma que facilite la formación de mayorías claras (por ejemplo, con la introducción de fórmulas electorales mayoritarias, en vez de proporcionales), de modo que el partido político mayoritario en la Asamblea escogerá a un Gobierno de su mismo color.

Cuando esta situación se produce, el ciudadano percibe una imagen del funcionamiento real del sistema parlamentario que poco se parece a la teoría: ya no hay un Gobierno que es controlado por el Parlamento, porque en realidad, el mismo partido domina uno y otro órgano, convirtiéndose en "el Príncipe Moderno" (Presno Linera, 2000). La Asamblea acaba convirtiéndose, así, en una mera cámara de registro de cuanto decide el Ejecutivo: merced a la disciplina de voto, cualquier iniciativa gubernamental resulta inmediatamente respaldada por todos los diputados del partido del Ejecutivo que, al disponer de mayoría, la convierten en voluntad parlamentaria. En esta tesitura, plantearse que el Parlamento pueda exigir responsabilidad política al Gobierno resulta casi impensable, ya que el mismo partido político -con miembros sujetos a una disciplina de voto- domina el Gobierno y el Parlamento.

Esta circunstancia ha dado lugar, incluso, al cambio en el sentido originario que tenían algunas instituciones de control, como se aprecia claramente por ejemplo en el caso español. Así, las preguntas e interpelaciones parlamentarias son, a menudo, meras cuestiones retóricas, que emplean los diputados del partido del Gobierno para que los ministros se luzcan. Es más, en ocasiones incluso se instrumentalizan los "tempos parlamentarios": el Reglamento de la Cámara baja española, por ejemplo, da preferencia a las interpelaciones provenientes de los grupos parlamentarios que menos uso hayan realizado de ellas (art. 182.2 del Reglamento del Congreso de los Diputados). Pues bien, el partido afín al Gobierno puede renunciar a lo largo de la legislatura a interpelar al Gobierno, para empezar a hacerlo (con cuestiones inofensivas para los ministros) a final del mandato, cuando las elecciones están ya próximas y resulta más conveniente que la ciudadanía se quede con una imagen positiva del Gobierno. Así, esta "reserva de interpelaciones" le permitirá que las suyas sean las que se debatan mayoritariamente cuando los comicios estén próximos. Algo parecido sucede con otros instrumentos de control, cuyo uso también desvirtúan los partidos políticos: en ocasiones las Comisiones de Investigación no se han utilizado para controlar al Gobierno en activo, sino al Ejecutivo anterior lo que, en realidad, supone que el partido vencedor en unas elecciones controle al partido que las ha perdido y al que ha reemplazado al frente del Gobierno. 
La situación se agrava por la peyorativa imagen que han ido adquiriendo los propios partidos políticos, que cada vez cuentan con una mayor desafección popular. Parte de esta pérdida de confianza se debe a factores tales como la estructura oligárquica que presentan muchos de las formaciones políticas (con ausencia de selección de los líderes a través de elecciones primarias y una falta de procesos deliberativos en la adopción de decisiones), un sistema de financiación que prima las aportaciones privadas o una percepción de que los partidos se integran por sujetos que cuentan con un estatuto privilegiado y que representan una auténtica clase que vive sólo de su carrera política (Presno Linera, 2014, pp. 227-233).

En otros sistemas, la presencia de grupos de presión también desvirtúa el funcionamiento teórico del sistema representativo. Bien es cierto que los regímenes actuales tienden a vetar el mandato imperativo, pero ello no impide que el votante tenga fundadas expectativas de que el candidato que ha elegido se ajuste al programa electoral con el que ha concurrido a los comicios. Sin embargo, esta relación entre el votante y el representante, basada en el programa electoral como una suerte de contrato oficioso, se ve desvirtuado por la presencia de grupos de presión que actúan imponiendo a los gobernantes sus aspiraciones en lo que sí que se parece a un mandato imperativo.

El impacto de los lobbies en el sistema democrático puede, además, resultar facilitado por una deficiente regulación normativa de la financiación electoral y de los partidos políticos. Desde luego, el debate sobre si debe existir o no financiación pública es un tema complejo (Presno Linera, 1999, pp. 210-215), pero lo cierto es que permitir una financiación exclusivamente privada de las campañas electorales puede abrir las puertas al endeudamiento de los partidos y, por lo mismo, a que luego sufran una suerte de "extorsión" cuando las entidades financiadoras exijan que se cumplan sus exigencias como contrapartida por el respaldo económico. Previsiones tales como que las donaciones privadas a los partidos no sean finalistas resultan baladíes: es obvio que ninguna empresa formalizará un contrato en el que se explicite una financiación condicional a un partido, pero la existencia en sí misma de una deuda coloca al partido político en una situación de dependencia.

El hecho de que los partidos parezcan fagocitar todo el sistema político o que haya lobbies que actúen en la sombra orientando las políticas de los órganos constitucionales conducen a un clima de desconfianza, o de desafección, por parte de la ciudadanía respecto del sistema representativo (Presno Linera, 2015, pp. 137-162). ¿Para qué disponer de un Parlamento -se preguntan algunos votantescuando en realidad quien decide es el partido mayoritario, que controla al tiempo al Ejecutivo y al Legislativo? ¿No es eso más que una dictadura de partido, que niega la premisa básica de la división de poderes? ¿Y para qué votar en unas elecciones si al final quien orienta la política nacional no son los ciudadanos con sus elecciones, sino los grupos de presión? 
Esta crisis en el funcionamiento real del sistema representativo ha conducido a dos tipos de situaciones. La primera es la lógica pulsión ciudadana por instrumentos de democracia directa. Estos suponen un atajo democrático, ya que permiten prescindir del sistema representativo, con sus partidos políticos y grupos de presión, al punto de verse como la más prístina manifestación de la soberanía popular: entre el pueblo y la decisión final que adopte no existen intermediarios. La otra situación consiste en la irrupción de nuevos partidos políticos y agrupaciones electorales que se describen como populares y ajenas tanto a los "partidos políticos tradicionales" como a los grupos de presión.

A menudo, estas formaciones se reivindican como agrupaciones transparentes, cuya financiación resulta visible para que el electorado no albergue sospechas de posibles clientelismos. Venderse como un candidato ajeno al "establishment", como ha hecho Donald Trump, aporta réditos electorales, porque el sistema mismo se percibe como algo que ha ido corrompiéndose y no sirve al propósito para el que fue ideado, a saber, representar los intereses del pueblo. Es más, resulta paradójico que el hecho de ser un magnate, como Trump, se convierta en un punto a favor del candidato, al considerar que su desahogada posición económica le convierte en un sujeto más independiente, que no necesita recurrir a empresas o grupos de presión que puedan condicionar su futura política. Un argumento, en realidad, que recuerda al que se empleaban los liberales que defendían el sufragio censitario: la ausencia de necesidades económicas como garantía de la independencia y como evidencia de que sólo estaría movido por el bienestar público, y no por el pedestre interés privado.

Este tipo de formaciones y de candidatos que se autoproclaman ajenos al sistema se perciben inmediatamente como un peligro para los partidos políticos tradicionales, desconcertados, por otra parte, por el extraordinario apoyo electoral que atesoran. La reflexión que ha de hacerse es que ese apoyo deriva, como he tratado de demostrar, del hecho de que los ciudadanos ya no perciben que el sistema representativo funcione correctamente ni que sirva para canalizar sus aspiraciones. Estar fuera del sistema de partidos o renegar explícitamente del lobby system da la apariencia de un retorno a la democracia más limpia de impurezas.

\section{La imagen del pueblo en perpetua minoría de edad}

Si el Ilamado "populismo" ha bebido en la desafección de la ciudadanía por la actual operatividad del sistema representativo, también lo ha hecho por la soberbia consideración por parte de los políticos de que el pueblo se hallaba en una perenne situación de minoría de edad o de incapacidad que le impedía conocer la trascendencia de ciertas decisiones que, de resultas, debían quedar al margen de su facultad de decisión. 
Un ejemplo claro puede hallarse en el proceso de construcción europea (Moreno Juste, 2001, pp. 97-101). La ciudadanía ha quedado totalmente al margen de la formación primero de la Comunidad Económica Europea y, más tarde, de la Unión Europea. Hubo algunos plebiscitos, bien es cierto, pero en ellos faltaba información suficiente y sólo se mostraba la idoneidad de construir un proyecto común entre los europeos, sin que trascendiesen datos tan importantes como la merma de soberanía (y por tanto de capacidad de decisión) que ello entrañaba. En definitiva, se ha tenido al pueblo como a un tutelado, excluido de las negociaciones, y al que finalmente se apelaba (si era necesario o conveniente) por vía de un plebiscito que, en realidad, pretendía ser apenas una ratificación.

Parece claro que este modus operandi responde a planteamientos más propios del despotismo ilustrado que de la democracia de los siglos XX y XXI. Pero incluso muchos teóricos del despotismo ilustrado (por ejemplo algunos fisiócratas) consideraban que la guía paternal del Monarca tenía un carácter básicamente transitorio, ya que la "minoría de edad" del pueblo respondía sólo a su falta de educación. Si el programa ilustrado de formar al pueblo acababa prosperando, ese nuevo pueblo culto estaría ya en condiciones de irse desprendiendo de la tutela paternal del Rey, no ya para crear una república (aspiración, obviamente, negada por el despotismo ilustrado), pero sí al menos para contar con instituciones representativas a través de las cuales pudieran hacer oír su voz.

En la actualidad, sin embargo las decisiones políticas se han adoptado con demasiada frecuencia de espaldas a los ciudadanos. Cargando todo el peso en la representación política, se menospreciaron tanto la fase de output (dar a conocer a los ciudadanos los pormenores de las cuestiones políticas que se estaban planteando) como la de input (permitiendo mecanismos de participación directa para conocer la opinión y voluntad ciudadanas). Es cierto que la complejidad de algunos procesos (las negociaciones de paz en Colombia, el Brexit en Gran Bretaña, o la integración europea) puede parecer poco compatible con los instrumentos de democracia directa ya que estos, laminan buena parte del pluralismo político al operar sobre un código binario. Pero no es menos cierto que ello no impide que sea conveniente su uso en cuestiones de especial trascendencia. Ahora bien se necesita, para ello, contar con dos aspectos: por una parte, que los ciudadanos reciban una fluida y completa información por parte de la Administración, lo que les permitirá decidir con fundamento suficiente. La complejidad de ciertas cuestiones políticas y económicas no puede servir de excusa, ya que el derecho de los ciudadanos a recibir información resulta una condictio sine qua non de una democracia madura (Villaverde Menéndez, 1995). Así como el paciente ha de recibir por parte de las autoridades sanitarias información inteligible de su estado de salud, por más complejo que sea el historial clínico, del mismo modo los gobiernos tienen que transmitir en términos adecuados y comprensibles las cuestiones referentes a los procesos políticos. El segundo aspecto que ha de tenerse presente en el uso de la democracia directa es que ésta no debe reducirse 
a la fase final del proceso (referéndum o plebiscito) sino que deben articularse mecanismos que habiliten una participación frecuente en los anteriores tramos del proceso. El trámite de audiencia en los actos administrativos previsto en algunos sistemas democráticos debería trasplantarse a aquellas decisiones políticas de especial trascendencia, en las que los ciudadanos tienen, por tanto, un interés más acusado.

El Ilamado "populismo" tiende a aparecer cuando, considerando al pueblo como sujeto inimputable, los gobernantes no atienden a las fases de output e input que han de ligarlos a la ciudadanía. Un pueblo mal informado (fallo del output) o al que sólo se le consulta al final del proceso y sin información continuada y suficiente (fallo en el input) puede ser más fácilmente guiado por quienes le suministren información más accesible pero quizás no del todo cierta, del mismo modo que, sintiéndose ninguneado en el proceso deliberativo, el pueblo puede sancionar a los gobernantes votando en contra de los deseos de aquellos en una consulta popular a la que ha sido llamado a última hora y con una intención principalmente ratificadora.

En este sentido, cuando se habla de "democracia plebiscitaria" el sentido que se le atribuye suele ser peyorativo: la participación directa sólo se utiliza para reforzar la decisión ya adoptada de antemano, logrando el apoyo popular por vía de una información deficitaria o por una formulación deficiente de los términos de la consulta popular. Justo lo contrario de cuanto debiera admitirse en un sistema verdaderamente democrático. La situación se asimilaría a las cuestiones de confianza tal y como se articulan en alguno sistemas parlamentarios: el Presidente del Gobierno es quien decide cuándo plantear ante el Parlamento esa cuestión de confianza, de modo que sólo hará uso de ella cuando sepa que cuenta con un apoyo suficiente y que, de resultas, su posición política resultará reforzada. De este modo, un mecanismo concebido para exigir responsabilidad política al Presidente se transforma en un instrumento en las manos de este último para consolidar su posición.

\section{El cambio en el discurso político}

En términos de la teoría de los sistemas de Niklas Luhmann (1995, 1996), creo que es acertado considerar que los sistemas jurídicos requieren, para ser operativos, de una reducción de la complejidad, de modo que las demandas sociales (entorno) se transmitan a él (inputs) debidamente cribadas. Precisamente los partidos políticos son un factor de reducción de complejidad social, al servir para canalizar las demandas sociales, reduciéndolas a un número determinado de formaciones que son las que aspiran a convertirlas en decisiones públicas. 
Ahora bien, debido en parte a la ya mencionada crisis en la percepción ciudadana del sistema representativo, el pueblo busca nuevas formas para canalizar sus demandas, tratando de reconstruir el sistema de partidos políticos. En efecto, en muchos casos se considera que el sistema representativo y los partidos dejan de ser válidos para reducir la complejidad, en particular cuando las opciones en presencia son vistas como idénticas por el electorado. En ese caso, la reducción de complejidad es excesiva, al punto de que, bajo la percepción del ciudadano, se pierde la esencia misma de la democracia (existencia de varias opciones) que queda reducida a una única posibilidad. Este discurso es el ofrecido por partidos y candidatos de "nuevo cuño". La idea que subyace es que ellos son los únicos que representan algo nuevo, en tanto que los restantes partidos políticos son, todos ellos, una misma cosa. Se subraya lo que tienen en común (connivencia con el lobby system, adscripción a un sistema representativo que no funciona...) para reducirlos a una misma versión, frente a la cual se erigen los nuevos partidos o candidatos.

El objetivo, por tanto, es realizar una nueva reducción de la complejidad, en este caso para poner al ciudadano en la disyuntiva de "o nosotros, o los partidos/ candidatos clásicos". Todo lo que no sea el "nosotros" se mete en una misma categoría, al margen de cualesquiera discrepancias ideológicas que puedan existir entre las restantes fuerzas políticas ${ }^{3}$.

Otra alternativa, ya mencionada, consiste en reclamar la presencia de institutos de democracia directa. En este caso, se considera que el sistema representativo no es el mecanismo adecuado para transmitir desde la sociedad al Estado las demandas ciudadanas. El input llega desvirtuado (los partidos no lo canalizan correctamente) y otro tanto sucede con el output (por ejemplo por la intervención de los grupos de presión). Así pues, se busca una alternativa, un mecanismo más fiable de "reducción de la complejidad", que parece hallarse en el uso de referéndums y plebiscitos. Sin lugar a dudas, en ellos se produce ese efecto deseado: la decisión la adopta directamente el cuerpo electoral sin intermediarios. Y ello aunque las consultas populares tengan evidentes limitaciones: por una parte, la reducción de la complejidad de las aspiraciones sociales puede resultar excesiva, ya que se opera con un código binario (o en su defecto con muy pocas alternativas), lo cual repercute también en una merma del pluralismo político; por otra, muy a menudo estas consultas populares son "dirigidas", es decir, nacidas a iniciativa de los poderes públicos que, por lo mismo, fijan el contenido de la cuestión que se somete a consideración popular, y con ello puede controlar hasta cierto punto el sentido del voto.

Esta dicotomía se percibe con claridad en el discurso del partido político español "Podemos" que habla de las restantes formaciones políticas como "partidos de casta", es decir, agrupaciones arraigadas que han profesionalizado la política, al margen de que su ideología sea de izquierdas, centro o derechas. 
En realidad, tanto los instrumentos de democracia directa como los nuevos partidos suelen tener en común unas idénticas pretensiones de reducir la complejidad de las demandas sociales en términos mayores de como se venía haciendo hasta ahora. Basta comprobar cómo el discurso político de algunas de estas formaciones tiende a buscar simplificaciones y se construye en torno a un lenguaje bipolarizado que, por otra parte, está en la base de su propia naturaleza ("nuestro partido frente a todos los demás").

Esta simplificación del discurso de los partidos que hoy se tienden a catalogar como "populistas" se manifiesta particularmente en aquellos que optan, además, por un programa de tintes nacionalistas. El nacionalismo tiene, obviamente, una doble cara. Por una parte, se encuentra aquel que intenta reforzar la NaciónEstado, como sucede con los partidos radicales de la ultraderecha o, por ejemplo, el caso de formaciones como el Partido Socialista Unido de Venezuela o, más recientemente, la postura evidenciada por Donald Trump. Es obvio que entre unos y otro existe un abismo ideológico, pero la dinámica nacionalista es un elemento que muestran en común: se potencia lo propio y se recela de lo exterior, de donde se considera que proceden todos los males. Así, el paro es fruto de la inmigración; las crisis de la empresa nacional es fruto de las importaciones; la delincuencia es el resultado de la falta de integración de los extranjeros; la inflación es consecuencia de los manejos de multinacionales de patrimonio extranjero, y las crisis políticas es el resultado de la intervención de gobiernos foráneos. El discurso, pues, se simplifica, y de este modo se pretende llegar a una capa de población mayor; se trata de convencer mediante mensajes simplistas que, por otra parte, evocan sentimientos y promueven la respuesta visceral del votante.

Por otra parte están los nacionalismos "periféricos", esgrimidos por formaciones políticas que, dentro de un Estado, aspiran a forjar una idea de Nación propia que conduzca a la creación de un Estado independiente. En este caso, el proceso es un tanto más complejo, ya que requiere articular el discurso en dos fases: la primera consiste en intentar arraigar la idea de que la población de una determinada región conforma una "Nación". A tales efectos, se tratan de hallar elementos identitarios, ya sean raciales, ya culturales o históricos. Para tal proceso se recurre, con frecuencia, a manifiestas simplificaciones que se construyen -una vez más- a partir del lenguaje excluyente del "nosotros" frente a "ellos". Esta es solo una de las simplificaciones en que incurren los nacionalismos; otra sería el discurso es reduccionista en términos territoriales: las grandes naciones-Estado deben -a su entender- quedar reducidas a unidades más pequeñas en las que los problemas parecen poder manejarse de forma más adecuada. La culpa de los problemas propios se imputa al exterior, a elementos extraños, es decir, a una complejidad que no se maneja. Y la solución que se pretende aportar es a través del autogobierno: gestión de los problemas propios (y no de los restantes). 
Supuestamente ensamblado el concepto de Nación, se considera que su conversión en Estado es una consecuencia lógica, y a tal fin orientan sus esfuerzos, dando lugar a la segunda fase de su programa. Para ello se recurre en ocasiones a una nueva simplificación: diferenciar entre legitimidad y legalidad. Si la legalidad constitucional no habilita a la segregación de ese territorio (para que se convierta en un Estado), se alega que la decisión resulta amparada por la legitimidad que les asiste, como Nación, para transformarse en Estado. El uso de instrumentos de democracia directa (una vez más, mecanismos que mal utilizados pueden resultar simplificadores) se convierte a menudo en un desiderátum para transitar de Nación a Estado, convocando, por ejemplo, plebiscitos, ya sea dentro ya, incluso, fuera de la legalidad constitucional.

Disociar legalidad y legitimidad es, de nuevo, una forma de simplificar el discurso, orientándolo de nuevo a un código binario: "los otros - diría este discursoquieren imponernos la legalidad, pero a nosotros nos asiste la legitimidad". Con este planteamiento, se identifican legalidad e imposición, por un lado, y legitimidad y libertad, por otro. Del mismo modo, hablan de Estado democrático, pero no de Estado de Derecho. Una perversión del lenguaje, puesto que no hace falta demostrar que sin un respeto por las formas jurídicas no sólo no existe orden público, sino tampoco auténtica libertad ni democracia.

\section{El nuevo "cuarto poder"}

Históricamente la prensa ha ejercido un papel determinante para la vida política de los Estados (Habermas, 1981). Ese cometido fue progresivamente compartido con los otros medios de comunicación que relegaron parte de su protagonismo: radio y televisión. Ahora bien, en tanto la prensa siempre tuvo un desarrollo más plural, al hallarse siempre en manos de la iniciativa privada (a excepción, obviamente, de las dictaduras que a estos efectos no nos interesan), el carácter de servicio público de la radio y de la televisión permitió que las empresas de particulares tuvieran que competir con los servicios directamente ofrecidos por la Administración Pública. La regulación, pues, de la radio y la televisión públicas se convirtió en una cuestión capital ya que su dependencia financiera de los Presupuestos Generales del Estado podía fácilmente convertirlas en instrumentos al servicio de los partidos políticos que asumiesen el Gobierno de turno. Una situación que podría conferirles una posición privilegiada ante el electorado, a base de proporcionar información sesgada que sirviese a sus propósitos.

Sin embargo, la relación existente entre estos medios de comunicación "tradicionales" (prensa, radio y televisión) y la ciudadanía se ha visto modificada en los dos últimos lustros. Cada vez resulta más frecuente que exista una brecha entre el seguimiento de los medios de comunicación y las preferencias electorales. Así, por ejemplo, en España el periódico más vendido es El País, ideológicamente 
vinculado con el Partido Socialista Obrero Español, y la radio más escuchada es La Ser, perteneciente al mismo grupo editorial. Sin embargo, el PSOE ha sido severamente castigado en las dos últimas elecciones, y se halla inmerso en una crisis que lo ha relegado en muchas regiones a tercera fuerza política.

No debe desconocerse, sin embargo, que la realidad de los medios de comunicación actuales poco tiene que ver con aquellos diarios modestamente elaborados por periodistas, literatos o empresarios con vocación política. Hoy constituyen simples empresas de comunicación, que en muchos casos poseen un auténtico holding (el caso de Silvio Berlusconi en Italia ha sido el más significativo), con la titularidad de diarios, empresas radiofónicas, editoriales y canales televisivos. Por lo mismo, esa mercantilización de la información ha convertido a estos grupos empresariales en víctimas de su propio crecimiento. La independencia informativa que predican no siempre es tal, ya que emporios de esas dimensiones acaban obligando a servidumbres económicas con bancos o, incluso, con los propios Gobiernos nacionales.

El resultado es que, así como parte de la sociedad recela a día de hoy de lo que llaman "partidos tradicionales", hace otro tanto de esos medios de comunicación. También estos últimos serían presa de los grupos de interés (sobre todo económicos) que viciarían sus mensajes y modularían la información que transmiten. No es ya que esos medios de comunicación emitan una información matizada políticamente según sus preferencias (algo con lo que se cuenta, y que está implantado históricamente desde los orígenes mismos de la prensa), sino que el matiz respondería a intereses más espurios: la conveniencia económica del grupo empresarial titular del medio de comunicación.

Todo ello ha conducido a un distanciamiento progresivo de la sociedad respecto de los medios de comunicación "tradicionales" que han venido cumpliendo un papel importante para la formación de la opinión pública y, por tanto, para la democracia. Estos medios ya no pueden esgrimir con propiedad su posición de "cuarto poder", ya que han perdido claramente esa influencia de la que antaño gozaban. La sociedad busca, pues, otras vías para obtener la información que necesita, y hoy en día cuenta con una herramienta que sirve perfectamente a ese propósito: internet. La extraordinaria libertad con la que cuenta internet es percibida por la ciudadanía como un factor positivo, ya que cualquiera puede exponer su opinión, o difundir una noticia, sin que (al menos en apariencia) lo haga por intereses comerciales espurios. Y aunque así fuera, el debate abierto, la constante contrainformación y, en definitiva, el flujo continuo de opiniones (web 2.0) servirían como contrapeso, y permitirían a los lectores sacar sus propias conclusiones. 
Es evidente que en la actualidad, muchos "blogueros" son mucho más influyentes que cualquier medio de comunicación "tradicional". Sobre todo, huelga decirlo, entre los jóvenes, ya que el aspecto generacional resulta muy importante en este punto. Por eso, a medida que el electorado sea más joven, más necesitan los Gobiernos y los partidos políticos de internet para llegar a él (Cotarelo, 2010). Porque la red global se ha convertido en su medio habitual para comunicarse y relacionarse socialmente. Aun así, la sociedad suele recelar cuando el mensaje procede de emisores institucionales, porque lo importante no es sólo el medio (internet) sino también, en efecto, quién hace uso de él. Se prefiere siempre al emisor considerado como imparcial, porque carece de una posición institucional visible y, de resultas, se presume que carece de lastres que contaminen su opinión. Descartados los profesionales de la política, también se recela de los profesionales de la información. En realidad, esta nueva orientación del ciudadano encaja con la preferencia por mecanismos de democracia directa: así como los ciudadanos reniegan del sistema representativo (es decir, de intermediarios) y buscan reemplazarlo por sistemas de democracia directa, también a la hora de conseguir información renuncian a los intermediarios (profesionales de la información) y buscan directamente la información que desean a través de internet; un medio que posibilita además una relación bidireccional.

En este sentido, la libertad de expresión ha sustituido -como mecanismo para formar la opinión pública- a la libertad de información. Lo cual entraña un riesgo, ya que esta última está sujeta en muchos ordenamientos jurídicos al deber de veracidad, aspecto que obviamente no puede trasladarse a la libertad de expresión. Otro riesgo es el desconocer quién se halla tras esas opiniones o noticias difundidas por la web o, lo que es lo mismo, la desprofesionalización y la dificultad para exigir responsabilidad por informaciones falsas que se puedan difundir (problema que ha resultado visible en las recientes elecciones presidenciales estadounidenses). El reto constitucional es cómo limitar esas informaciones falsas que pueden desvirtuar los procesos electorales, y cómo hacerlo sin limitar la libertad de expresión, y sin incurrir en conflictos de extraterritorialidad, al ser muchas webs de procedencia extranjera (tanto los autores de la web como los operadores). Un tercer peligro, en este caso tecnológico, es el posibilitar que la información y opiniones lleguen a nosotros a través de algoritmos cuyo diseño desconocemos. En efecto, precisamente porque internet posee una cantidad de información inabarcable, se hace preciso el uso de buscadores (browsers) que filtren los datos que buscamos (una vez más un proceso de simplificación de un sistema social). De ahí se deriva la importancia de lo que se denomina el "posicionamiento": ante el volumen de información disponible, sólo se suelen consultar los primeros resultados que ofrece el buscador, de modo que situarse en los primeros puestos garantiza una lectura más amplia que, a su vez, se retroalimenta (más lectores generan mejor "posicionamiento"). Ahora bien, desconocemos cómo están programados los algoritmos sobre los que operan esas búsquedas y, de resultas, cualquier pesquisa informativa queda a expensas del "posicionamiento" que Google, u 
otras multinacionales del mismo ámbito, decidan. El hecho de que existan incluso empresas dedicadas a mejorar ese "posicionamiento web" pone de manifiesto que es posible realizar operaciones para falsear la ubicación de los resultados de las búsquedas que, por tanto, no dependerán de la importancia o veracidad de la información suministrada, sino de factores meramente empresariales.

Otro riesgo adicional de esta información a través de internet es el hecho de que cambie igualmente el código para transmitir el mensaje. Herramientas como twitter han supuesto una reducción de la complejidad excesiva, al tratar de condensar información relevante en apenas unas pocas palabras. Twitter podría servir como objeto de análisis informativo (sus mensajes tienen virtualidad como fuente de estudio para proveedores de información), pero difícilmente pueden servir como medio informativo en sí mismos. A pesar de ello, la ciudadanía se ha ido acostumbrando a esta forma fugaz de transmitir datos, pretendiendo que problemas complejos se expliquen en pocas palabras. Eso justifica, en parte, por qué cada vez tienen más impacto los mensajes cortos y contundentes; los eslóganes simplistas, maniqueos y carentes de matices $\varphi$

\section{Referencias}

Cotarelo, R. (2010). La política en la era de internet. Valencia: Tirant lo Blanch.

De Otto, I. (1988). Derecho Constitucional. Sistema de fuentes. Barcelona: Ariel.

Gálvez Muñoz, L. A. (1991). La influencia de las encuestas electorales sobre los electores. En Estudios de Derecho Constitucional y Ciencia Política: homenaje al profesor Rodrigo Fernández-Carvajal 797-818. Murcia: Servicio de Publicaciones de la Universidad de Murcia.

Habermas, J. (1981). Historia y crítica de la opinión pública. Barcelona: Gustavo Gili.

Luhmann, N. (1995). Social Systems. California: Stanford University Press.

Luhmann, N. (1996). Introducción a la Teoría de los Sistemas. México: Anthropos.

Moreno Juste, A. (2001). El Movimiento Europeo y la definición de los valores democráticos en el proceso de construcción europea. Documentación Social, (123), 97-116.

Presno Linera, M. A. (1999). La reforma del sistema de financiación de los partidos políticos. Revista Española de Derecho Constitucional, (57), 205-228. 
Presno Linera, M. A. (2000). Los partidos políticos y las distorsiones jurídicas de la democracia. Barcelona: Ariel.

Presno Linera, M. A. (2014). "Partidos políticos y movimientos ciudadanos en la sociedad del riesgo y la desconfianza" En Presno Linera, M. A. (Coord.), La metamorfosis del Estado y del Derecho (213-252). Oviedo: Junta General del Principado de Asturias.

Presno Linera, M. A. (2015). Causas jurídico-constitucionales de la desafección ciudadana hacia el sistema representativo. En Sanjuán Andrés, F. J., Calabuig Puig M. A. y Tur Ausina, R. (Dirs.), Problemas actuales de derecho constitucional en un contexto de crisis. Granada: Comares.

Vera Estrada, A. (2008). ¿Las encuestas electorales influyen en los resultados? Investigación y marketing, (99), 32-37.

Villaverde Menéndez, I. (1995). Los derechos del público. Madrid: Tecnos.

Zanatta, L. (2014). El populismo. Buenos Aires: Kartz. 